\title{
Assessment of the energetic potential by hazelnuts pruning in Viterbo's area
}

\author{
D. Monarca, M. Cecchini, A. Colantoni, S. Di Giacinto, A. Marucci, L. Longo \\ Department of Agriculture, Forest, Nature and Energy (DAFNE), University of Tuscia, Italy
}

\begin{abstract}
In this work the amount of biomass available by the hazelnuts pruning in the province of Viterbo was investigated. At present, the pruning's residues are destroyed by farmers directly in the field, at the end of the pruning; in this way a large quantity of biomass, represented by hazelnut's prunings, is lost; the residues obtained from the hazelnut's pruning, are an important source of biomass that could be used for thermal energy production.

The aim of this work is to realize a map with the estimated energy potential from hazelnut pruning biomass, in the province of Viterbo.

In the first phase the amount of biomass obtained from a hectare of hazelnut's cultivationwas estimated:sampling were carried out in some municipalities of Viterbo while hazelnut pruning was taking place, from January to March.In the field, biomass was weighed and some pieces of wood were collected for laboratory analysis; in particular humidity of biomass, low calorific value, ashand the content of carbon $(\mathrm{C})$, hydrogen $(\mathrm{H})$ and nitrogen $(\mathrm{N})$ were determined. In the calculation of the biomass were considered the age of the plants and the number of plants per hectare.

The results show that the amount of biomass obtained from pruning of hazelnuts varies with the age of plants, but even more so by the number of plants per hectare. The average value of biomass obtained from pruning of a hectare of land is just under $0,9 \mathrm{t}$. Knowing the net
\end{abstract}

Correspondence: Massimo Cecchini, Department of Agriculture, Forest, Nature and Energy (DAFNE), University of Tuscia, Via S. Camillo de Lellis snc, 01100 Viterbo, Italy.

Tel.: +39.0761.357.357 - Fax: +39.0761.357.453.

E-mail: ergolab@unitus.it

Key words: biomass, hazelnut's pruning, energy potential from pruning, calorific value.

Contributions: the authors contributed equally.

Conflict of interests: the authors declare no potential conflict of interests.

Conference presentation: part of this paper was presented at the 10th Italian Conference AIIA (Associazione Italiana di Ingegneria Agraria), 2013 September 8-12, Viterbo, Italy.

(c) Copyright D. Monarca et al., 2013

Licensee PAGEPress, Italy

Journal of Agricultural Engineering 2013;XLIV(s2):e117

doi:10.4081/jae.2013.s2.e117

This article is distributed under the terms of the Creative Commons Attribution Noncommercial License (by-nc 3.0) which permits any noncommercial use, distribution, and reproduction in any medium, provided the original author(s) and source are credited. calorific value of the hazelnut wood and the number of hectares cultivated for each municipality, a map of thermal potential energy has been realized..

\section{Introduction}

Among the main treatments on crop management, there are thinning, pruning and fertilizing. These handlings are often applied simultaneously and they interact with each other. As a consequence, they influence the growth and crown of the crop, the branch sizes and the longevity (Forrester et al., 2012a). The three above-mentioned stages affect important aspects of the life crop such as transpiration, photosynthesis and water-use efficiency. From the study of these treatments and their interaction, it is possible to define an efficient and optimal crop management (Forrester et al., 2012b).

Biomass results from pruning crops operation represents an interesting and attractive resource to be exploited in different ways, e.g. fuel for energy production, or transformed into compost and later used as an organic fertilizer. In order to define the most appropriate use of residual biomass from pruning, the attention has to be focused on the amount of pruned material and its physical-chemical characteristics. The former depends on several parameters, namely the type of cultivation, the cultivation site and the planting distance. In case of intensive farming of walnut, hazelnut, olive, gr apevine, the pruned biomass reaches $538 \mathrm{~kg} / \mathrm{ha}, 1,848 \mathrm{~kg} / \mathrm{ha}, 2,524 \mathrm{~kg} / \mathrm{ha}$ and $4,255 \mathrm{~kg} / \mathrm{ha}$ respectively. Higher quantities of pruned biomass are achieved by apple and pear cultivation, leading to $5,557 \mathrm{~kg} / \mathrm{ha}$ and $5,818 \mathrm{~kg} / \mathrm{ha}$ respectively (Bilandzija et al., 2012).

With specific regard to hazelnut crop, in addition to pedo-climatic environment and plant age, the pruning cut method - i.e. manual or mechanical operations - strongly affects the amount of residual biomass and the health conditions of the plant itself.

In more detail, manual pruning leads to produce a higher quantity of biomass if compared to the mechanical method; nevertheless, a decrease in yield was noted for pruned trees. In case of mechanical pruning, an acceptable yield is already expected immediately after the pruning period and leading to a better quality of hazelnut (Sonnati et al., 2009). The intensity of pruning operations in hazelnut cultivations affects the amount of woody biomass and the development of the crop itself. Furthermore, the penetration of light is deeper in the case of a high pruning intensity; in the short term, the yield is greater when low pruning intensity occurs, but higher productivity and growth of the cr op result from high-pruning intensity in the long period (Cristofori et al., 2009). The pruning period is strongly linked to the cultivation yield: a limited influence is expected in April, May, June or July, while a significant increase is shown two or three years later after pruning (Ughini et al., 2009).

The biomass resulting from hazelnut plants pruning can be seen as a suitable solution to produc e energy by means of thermo-chemical processes, namely combustion, gasification and pyrolysis. 


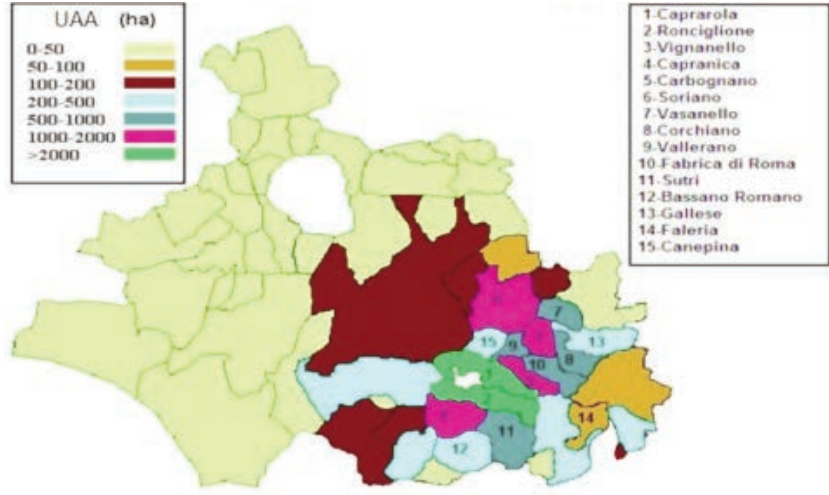

Figure 1. Main hazelnut productive areas in the province of Viterbo. The upper left shows the utilized agricultural area (UAA), with hazelnut cultivation (ha).

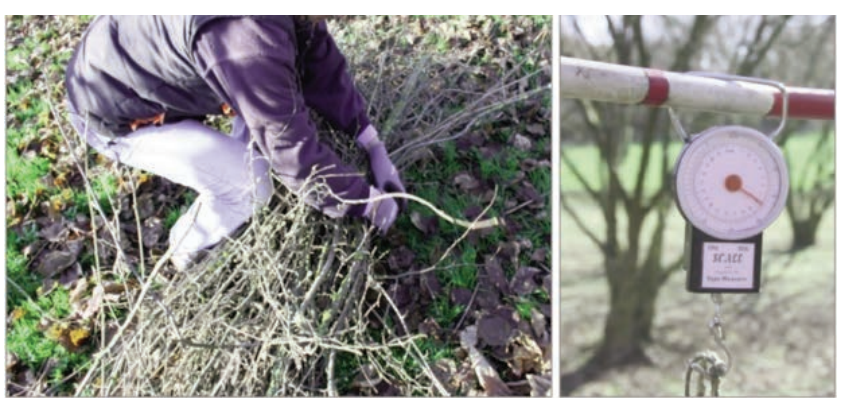

Figure 3. From left to right: bundles of pruned branches; weighting process with a dynamometer.

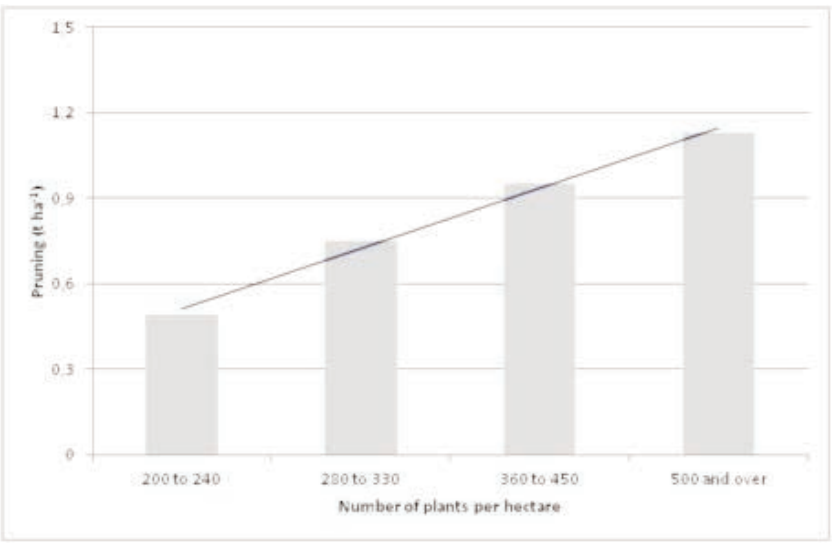

Figure 5. Pruning residues available related to the number of plants per hectare.

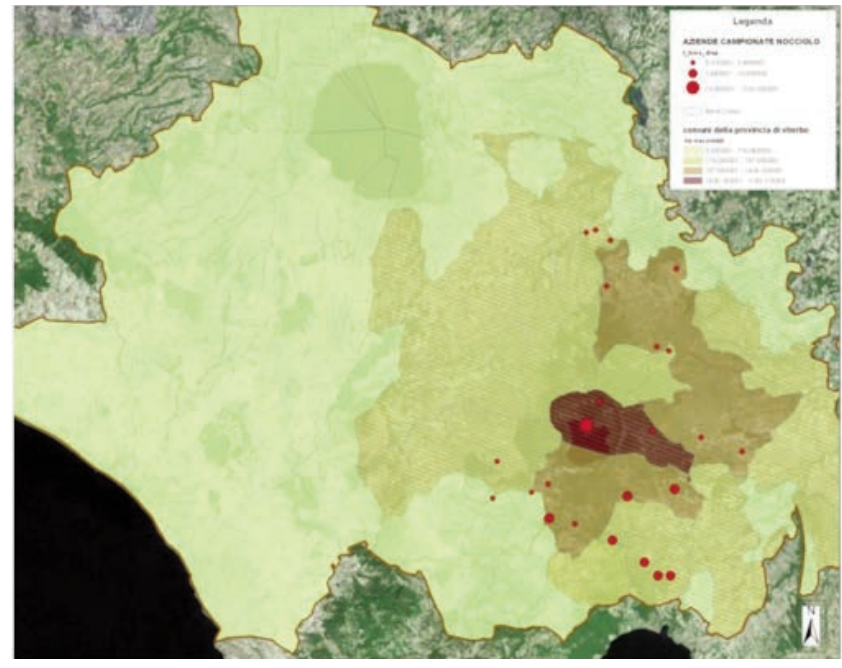

Figure 2. Farm localization and average of biomass.

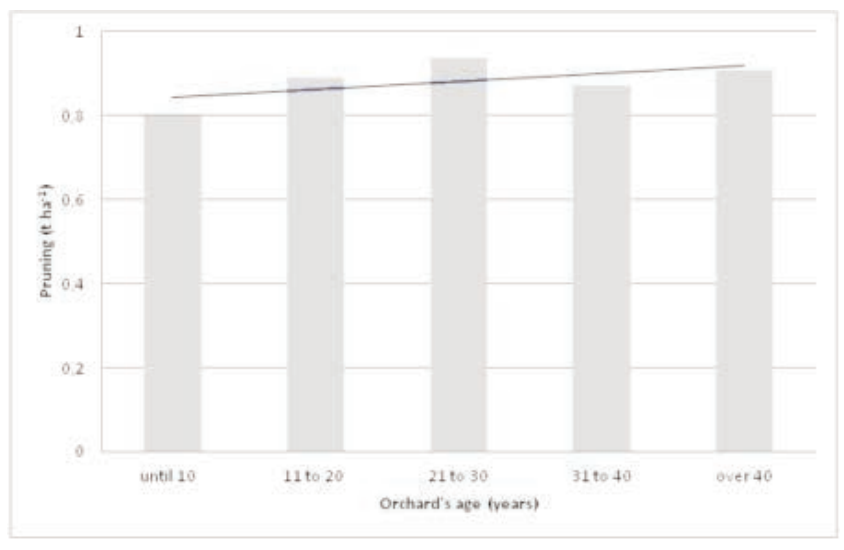

Figure 4. Pruning residues available related to the orchard's age.

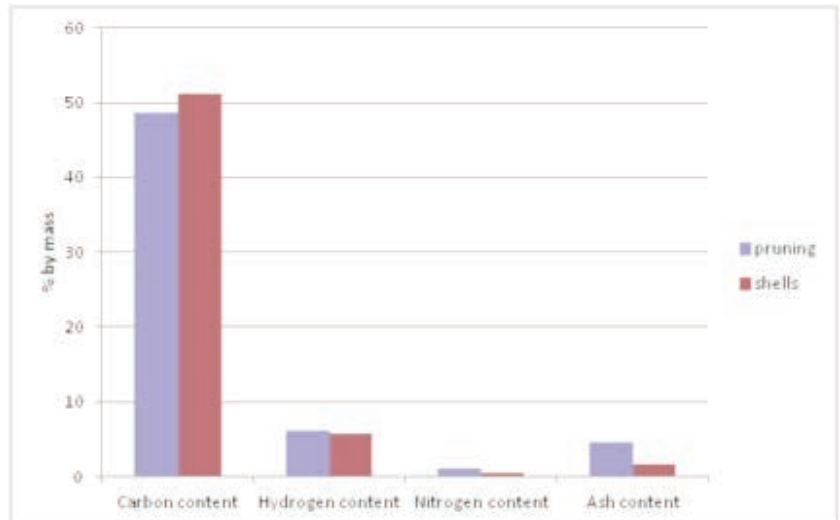

Figure 6. Comparison of biomass characterization between hazelnut pruning and shells. 
Table 1. Hazelnut diffusion in the province of Viterbo.

\begin{tabular}{|c|c|c|c|c|c|}
\hline $\begin{array}{l}\text { Number of } \\
\text { municipality }\end{array}$ & $\begin{array}{l}\text { Number of } \\
\text { municipality } \\
\text { with hazelnut cultivation }\end{array}$ & $\begin{array}{c}\text { Utilized } \\
\text { agricultural } \\
\text { area (UAA) (ha) }\end{array}$ & $\begin{array}{l}\text { Utilized } \\
\text { agricultural area (UAA), } \\
\text { with harelnut cultivation (ha) }\end{array}$ & $\begin{array}{c}\text { Number of } \\
\text { farm }\end{array}$ & $\begin{array}{l}\text { Number of } \\
\text { farm with } \\
\text { hazelnut cultivation }\end{array}$ \\
\hline 60 & 29 & 21.439 & 17.735 & 22.478 & 9.116 \\
\hline
\end{tabular}

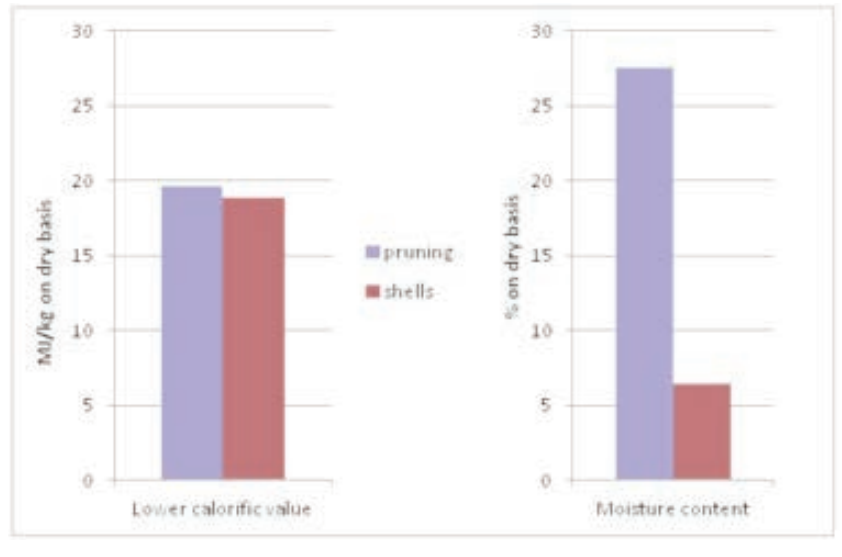

Figure 7. From left to right, lower calorific value and moisture content for hazelnut pruning and shells.

The present work is aimed at preliminarily evaluating the possible creation of small energy districts in the area of Viterbo (also called Tuscia, in central Italy) (Monarca et al., 2009). This opportunity depends on the amount of available biomass and its conversion technology, since gasification proc ess can be hardly implemented in large scale applications (Monarca et al., 2011). With specific regard to its use as organic fertilizer, the content of nutrient elements and the decomposition level of hazelnut husk - in terms of variations in $\mathrm{C} / \mathrm{N}$ ratio, organic matter content, organic carbon and nutrients - need to be further investigated and appropriately estimated (Özenç and Özenç, 2009).

This paper sh ows a study about the amount and use of pruning biomass, particularly about the pruning of hazelnut plants of 25 farm sited in the south-east area of the province of Viterbo.

Two main aspects will be underlined: pruning energy characterization - in terms of calorific value, moisture and CHN content - and availability and distribution in the Province of Viterbo. The former leads to identify the most suitable conversion technology to produce energy from biomass; the latter is addressed to define the potential area where biomass is generated and is strongly related to the location of the plant.

\section{Materials and methods}

The crops selected for the present survey are located in some of the most productive areas in the Province of Viterbo; they weren't representatives of the most-spread crop system, because of the large heterogeneity of such a cultivation. The study was carried out on a sample of more than 200 hectares area and involved 25 company (Figure 2).

The pruning residues we considered, belong to the species Corylus avellana L., the cultivar was the Tonda Gentile Romana. For each selected hazelnut crop, surface measure, planting distance and number of trees per hectare were recorded (Table 2). Moreover, every lot was
Table 2. Sampled hazelnut groves: main characteristics.

\begin{tabular}{lcc} 
Planting distance $(\mathrm{m})$ & Number of trees ha-1 & Number of ha \\
$4.0 \times 4.5$ & 556 & 1 \\
$4.5 \times 4.5$ & 500 & 1 \\
\hline $5.0 \times 4.0$ & 500 & 22 \\
$5.0 \times 4.5$ & 450 & 8 \\
\hline $5.0 \times 5.0$ & 400 & 126 \\
$5.0 \times 5.5$ & 370 & 1 \\
\hline $5.5 \times 5.5$ & 331 & 16 \\
$6.0 \times 5.0$ & 333 & 8,5 \\
\hline $6.5 \times 5.0$ & 308 & 6 \\
$6.0 \times 7.0$ & 238 & 10 \\
\hline $6.5 \times 8.0$ & 192 & 2 \\
\hline
\end{tabular}

divided into sub-lots, according to the sampling standards (UNI EN 14778:2011), each one delimited by four plants.

Once pruning operations ended, the residual biomass in the sub-lot was bundled and weighted by means of a dynamometer (Figure 3). Weight measurements were carried out in field conditions. Woody samples were put into small closed plastic containers in order to determine chemical and physical characteristics in laboratory conditions.

Later, the average value of the pruning weight per hectare was obtained.

\section{Results}

The present study investigates two different aspects: available residual biomass derived from pruning in Corylus avellana L. trees and biomass energy characterization.

The sampled fields examined were divided into age classes - in the case of hazelnut trees - and number of trees per hectare. If we consider the age of the hazelnut tree, as shown in Figure 4, the highest quantities of hazelnut pruning are obtained from 21 to 30 years old-plants. With specific regard to over 40-plants, it seems that the amount of biomass does not show an increasing trend with age. This can be due to the following phenomenon: the over 40-tree volume stops growing. However, a significant difference does not occur if age classes are considered.

Focusing on the number of plant per hectare, a greater difference is noted: as the former increases, the amount of pruned biomass becomes higher, as it can be seen in Figure 5 .

In laboratory conditions, biomass characterization was effected. Moisture and ash content were determined on weight fraction on dry basis (wt. \% on dry basis). Carbon (C), hydrogen (H), oxygen (0) and nitrogen $(\mathrm{N})$ contents were determined using fraction on mass $(\%$ on mass). Also the lower calor ific value was determined as a MJ/kg on dry basis (Table 3 ). 
Table 3. Characterization of hazelnut pruning.

\begin{tabular}{lcc} 
Parameter & Value & Unit of measurement \\
Moisture content & 27.59 & \% on dry basis \\
Lower calorific value & 19.68 & MJ/kg on dry basis \\
\hline Carbon content & 48.69 & \% by mass \\
Hydrogen content & 6.17 & \% by mass \\
\hline Nitrogen content & 1.09 & \% by mass \\
Ash content & 4.54 & \% by mass \\
\hline C/N & 45.69 & \% by mass \\
\hline
\end{tabular}

The contents of $\mathrm{C}, \mathrm{H}, \mathrm{N}$ show that these biomass fuels have a higher share of carbon content compared to hydrogen and nitrogen, which increases their energy value.

If we compare the results coming from the energy characterization in laboratory, it can be stated that, with reference to the hazelnut shells, hazelnut trees pruning have similar values in terms of ash content, $\mathrm{C}, \mathrm{N}, \mathrm{H}, \mathrm{C} / \mathrm{N}$ and lower calorific value: Moisture content is higher in hazelnut residues (Figure 6 and 7 ).

\section{Conclusions}

Available residual biomass, obtained from hazelnut trees pruning, can be successfully considered as a real economical opportunity and as an attractive chance in the Province of Viterbo. The large quantities can supply the growing energy demand and can be efficiently used in domestic or district heating. The energy characterization in laboratory is an important step in choosing the most suitable conversion technology: since this type of woody biomass is similar to hazelnut shells, combustion or gasification seems to be the most appropriate solution (Monarca et al., 2012).

\section{References}

Forrester, D.I., Collopy, J.J., Beadle, C.L., Baker, T.G.; Interactive effects of simultaneously applied thinning, pruning and fertiliser application treatments on growth, biomass production and crown architecture in a young Eucalyptus nitens plantation; Forest Ecology and Management. 2012a). 267: 104-16.

Forrester, D.I., Collopy, J.J., Beadle, C.L., Baker, T.G.; Effect of thinning, pruning and nitrogen fertiliser application on transpiration, photosynthesis and water-use efficiency in a young Eucalyptus nitens plantation; Forest Ecology and Management. 2012b). 266: 286-300.

Bilandzija, N., Voca, N., Kricka, T., Matin, A., Jurisic, V. Energy potential of fruit tree pruned biomass in Croatia. Spanish Journal of Agricultural Research. 2012. 10: 292-8.

Sonnati, C., Faciotto, G., Ughini, V. Prune and recycle: mechanical hazelnut pruning and energetic recovery of its biomass. Acta Horticulturae. 2009. 845: 413-18.

Cristofori, V., Cammilli, C., Valentini, F.B., Bignami, C.; Effect of different pruning methods on growth, yield and quality of the hazelnut cultivar 'Tonda Gentile Romana'; Acta Horticulturae 845 , pp. 315$322 ; 2009$.

Ughini, V., Roversi, A., Malvicini, G.L., Sonnati, C. Effects of hazelnut summer pruning performed in different months. Acta Horticulturae. 2009. 845: 363-6.

Monarca, D., Cecchini, M., Guerrieri, M., Colantoni, A. Conventional and alternative use of biomasses derived by hazelnut cultivation and processing. Acta Horticulturae. 2009. 845: 627-34.

Monarca, D., Cecchini, M., Colantoni, A., Marucci, A. Feasibility of the electric energy production through gasification processes of biomass: technical and economic aspects. Lecture Notes in Computer Science (including subseries Lecture Notes in Artificial Intelligence and Lecture Notes in Bioinformatics). 2011. 6785: 30715.

Özenç, D.B., Özenç, N. Determination of hazelnut husk decomposition level and of the content of some plant nutrient elements under natural conditions. Acta Horticulturae. 2009. 845: 323-30. 